\title{
As práticas físicas, em Portugal, no Antigo Regime
}

\author{
José V. Ferreira ${ }^{1}$ \\ António G. Ferreira ${ }^{2}$
}

https://doi.org/10.5628/rpcd.03.03.56

\author{
${ }^{1}$ Faculdade de Ciências do Desporto e de Educação Física \\ Universidade do Porto, Portugal \\ ${ }^{2}$ Faculdade de Psicologia e de Ciências da Educação \\ Universidade de Coimbra, Portugal
}

\begin{abstract}
RESUMO
Não era propriamente novidade, nos finais do Antigo Regime, a preocupação relativa ao bem-estar e ao equilíbrio do corpo. De facto, médicos e cirurgiões portugueses do séc. XVIII bem consideraram o exercício físico como especialmente importante para a conservação da saúde das pessoas. No entanto, nas obras médicas e cirúrgicas da primeira metade do século, a preocupação dominante, senão a única, era a da preservação da saúde. Raramente, nelas se encontrava a preocupação com o desenvolvimento integral do indivíduo. Ora, na segunda metade do séc. XVIII, os médicos e pedagogos passaram a olhar a Educação Física como uma condição fundamental do desenvolvimento global do ser humano. Neste sentido, o exercício já não era particularmente entendido apenas como necessário à preservação da saúde, mas igualmente como factor de desenvolvimento físico, pilar importante da formação moral. A partir destas ideias, analisámos alguns documentos relativos a instituições educativas Portuguesas, tentando verificar quais as disposições implicadoras com o desenvolvimento do corpo dos alunos. Foi ainda nossa intenção constatar se havia uniformidade nessas disposições, bem como se nelas se reflectiam diferentes concepções educativas. Ora, da análise sobre as ideias e as práticas relativas à educação física, nos finais da segunda metade do séc. XVIII, vimos que elas se desenvolviam de acordo com duas tendências: de um lado, as práticas físicas e os jogos legados pela tradição e, do outro, concepções médicas e pedagógicas mais atentas às condições de desenvolvimento dos indivíduos, que se concretizavam em actividades de descontracção e de formação do corpo pensadas para se articularem com as de natureza intelectual. No entanto, as disposições contempladas nos planos de estudos dos colégios indicavam que se privilegiava uma concepção de educação física fundamentalmente higiénica ou tradicional, orientada por técnicas corporais de uma minoria social privilegiada, para quem o corpo se devia conformar a critérios de elegância, definidos por gestos plenos de formalismos, e também práticas corporais fundamentadas em preocupações higiénicas e pedagógicas, válidas para o desenvolvimento da população em geral.
\end{abstract}

Palavras-chave: práticas físicas, Antigo Regime, Educação Física, desenvolvimento do corpo, colégios portugueses.

\section{ABSTRACT \\ Physical Practices, in Portugal, in the Old Regime}

By the end of the Old Regime it was not properly a novelty the concern about body harmony and well-being. In fact, 18 th century Portuguese physicians and surgeons considered physical exercise particularly important to people's health. However, in the medical and surgical published work of the first half of the century, the dominant concern, if not the only one, was health maintenance. Rarely did we find any concern about a holistic approach of individual development. In the second half of the 18th century physicians and educators began to look at Physical Education as a basic condition for the holistic development of the human being. In this sense, physical exercise was not only seen as necessary for health maintenance, but also as a factor for physical development, important pillar of moral formation. Building on these ideas, our aim was to analyse some documents concerning Portuguese educational institutions, trying to verify the dispositions which had important implications to students' body development. It was also our goal to search for a prove of the uniformity in these dispositions, as well as to understand if different educational conceptions were reflected in them. A close inspection about these ideas and the views related to physical education, during the second half of the 18th century, showed the emergency of two main tendencies: on one side, the focus was on physical practices and traditional games legacy; on the other side, medical and pedagogical conceptions were the main concern. It is also important to relate to dispositions that were considered in the curricula of the schools that were oriented towards a hygienist and aesthetic formalism of body movements.

Key Words: physical practices, Old Regime, Physical Education, body development, Portuguese schools. 


\section{INTRODUÇÃO}

Durante o século XVIII assistiu-se a um crescendo interesse pela educação física, visível, sobretudo, na literatura médica e nas publicações de natureza pedagógica. Estudos mais recentes têm demonstrado que esse interesse teve reflexos na organização de algumas das instituições educativas de maior prestígio, surgidas, nos finais do Antigo Regime, em Portugal. Neste nosso trabalho, pretendemos apresentar, de forma sucinta, as principais linhas de pensamento sobre a educação física a vigorarem ao longo de Setecentos, para, a partir delas, analisarmos alguns documentos relativos a instituições educativas portuguesas, no sentido de verificarmos quais as disposições a terem implicações sobre o desenvolvimento do corpo dos alunos. Além disso, é nossa intenção identificar o alinhamento dessas disposições, verificando a sua uniformidade ou detectando diferentes concepções educativas. Entretanto, pretendemos apresentar mais alguns elementos que permitam ir compreendendo a verdadeira dimensão das práticas físicas praticadas no contexto dos estabelecimentos educativos portugueses do Antigo Regime.

\section{IDEIAS E PRÁTICAS FÍSICAS}

Não era propriamente novidade, nos finais do Antigo Regime, a preocupação relativa ao bem-estar e ao equilíbrio do corpo. De facto, médicos e cirurgiões portugueses, ao longo do século XVIII, bem consideraram o exercício físico como especialmente importante para a conservação da saúde das pessoas. No entanto, nas obras médicas e cirúrgicas da primeira metade do século, a preocupação dominante, senão a única, era a da preservação da saúde.

Raramente nelas se encontrava uma concepção de desenvolvimento integral do homem. Ora, na segunda metade do século XVIII, os médicos e os educadores mais ousados passaram a olhar a Educação Física como uma condição fundamental do desenvolvimento global do indivíduo. Neste sentido, o exercício já não era entendido apenas como conveniente à preservação da saúde, mas também como factor de desenvolvimento físico, base importante na formação do carácter e da moral das pessoas.

Sendo certo que a educação física havia ganhado importância, dado ser percebida quase como a arte de secundar a natureza humana, ela ainda não pos- suía um perspectiva didáctica, isto é, não contemplava um conjunto de disposições configuradoras de uma disciplina autónoma a exigir um espaço curricular. Ela aparecia na confluência da abordagem médica e das preocupações de pedagogos e moralistas, preocupando-se com os indivíduos desde a concepção, estipulando regras dietéticas, dando conselhos de higiene e prescrevendo certas formas de actividade, adequadas a cada idade (10, p. 50). Apesar do crescente impacto que tinha nos discursos pedagógicos, de então, ela não se impunha, no entanto, como uma disciplina ou área científica capaz de prescrever uma série de exercícios sistemáticos, fundamentados nas ciências médicas.

Independentemente desta evolução, as práticas físicas sempre existiram. Em geral, foram encaradas como actividades lúdicas ou de preparação militar. Com o Renascimento, a medicina e a pedagogia vão insistir na importância que elas tinham para a formação integral do indivíduo. A medicina, pelo menos, a partir dos finais da Idade Média, vai considerá-las como necessárias à saúde de cada um (23, p. 65 e 72); a pedagogia reforçou a medicina e influenciou a educação dos que queriam acompanhar a modernidade. Pelo menos a partir do século XVI, víamos os exercícios físicos a serem praticados em estabelecimentos escolares portugueses, inclusivamente nos dirigidos pela Companhia de Jesus (21, p. 471-479). Contudo, é a partir da segunda parte do século XVIII que se começou a acentuar uma maior preocupação com o desenvolvimento do corpo, traduzido em preocupações higiénicas e pedagógicas, onde, obviamente, estavam incluídos os exercícios físicos (Ibidem, p. 497-521).

Correspondendo a ideias avançadas por alguns intelectuais, nomeadamente, por Martinho de Mendonça, o Real Colégio dos Nobres iniciava em 1766 a sua actividade com o objectivo de preparar os meninos para funções próprias da aristocracia. Pelo horário fixado para as actividades dos alunos inscritos no referido estabelecimento de ensino, notava-se uma evidente preocupação com tempos apropriados para o desenvolvimento de actividades físicas. Se durante o Inverno existiam três períodos, dois designados por recreação e um outro por tempo livre, a poderem ser aproveitados para jogos e outras actividades de lazer, era no período do Verão, a começar 
pela Páscoa e a prolongar-se até Julho/Agosto, que surgia mais claramente definido um tempo destinado ao exercício físico. É certo que agora só o designado tempo livre se mantinha. No entanto, enquanto um deles era substituído pela sesta, o outro era precisamente destinado a disciplinas normalmente associadas pelos médicos e pedagogos ao desenvolvimento do corpo. Para este tempo estipulava-se pois que se reservasse, entre as 17 e as 19,30 horas, um espaço dedicado à prática da dança, da equitação e da esgrima (9, p. 403).

A mesma concepção educativa presidiu à organização de outras instituições educativas públicas e particulares. No Real Colégio de Mafra, estabelecimento destinado não só à educação dos filhos da nobreza, mas também à dos de "famílias honestas", o horário quotidiano imposto às crianças e aos jovens reproduzia o do Colégio dos Nobres, por isso, os tempos reservados às recreações e às actividades corporais de Inverno, como de Verão, eram os mesmos (17, p. 14 e 15). As indicações sobre as práticas físicas nos outros estabelecimentos nem sempre eram tão claras e pareciam traduzir uma diferenciação social. Nas escolas do Colégio de Alcobaça, dedicadas à "instrução da Mocidade Portuguesa", apenas houve o cuidado de conceder tempos de descanso para passeios e recreações, para que o corpo se retemperasse de tantas horas de contenção intelectual e física.

Esclareceu-nos o Regulamento que os passeios se efectuavam "pelas cercas immediatas ao Mosteiro (...), e Quinta do Collegio” (24, p. 88), realizando-se nos dias de estudo, depois das aulas, e nas tardes dos dias feriados, bem como nas tardes de quintafeira, caso não houvesse na semana dia santo. As recreações, porém, desenvolviam-se uma vez por mês, num dia feriado da semana e nas férias do Natal e da Páscoa (Ibidem).

O Colégio de S. Patrício, restabelecido por ordem de D. Maria I em 1784, parece ter olhado o desenvolvimento físico do mesmo modo. O plano de estudos deste estabelecimento de ensino referia-se "ao bem do corpo" e à "conservação da saúde" para justificar a necessidade de serem reservados tempos destinados a "recreio honesto e exercicio corporal util e não perigoso" (1, Ms. 4202), mas o lacónico documento não nos informou, contudo, do número de horas destinadas às actividades físicas, nem o que eram exercícios úteis e não perigosos. Seria o jogo da péla perigoso? E a esgrima?

Um documento semelhante, datado de 1791, referente à Casa de Educação e Colégio de Silvério, localizada igualmente em Lisboa, também era pouco esclarecedor quanto a este problema. Por um lado, dizia que pretendia ter um especial cuidado com o corpo e, por isso, reservava tempos destinados "às distrações, recreações e exercicios" (2, Doc. 5193); todavia, por outro, nada nos elucidava sobre os exercícios a praticar e permitir. Ficamos apenas a saber que no Verão as actividades recreativas ocupariam mais horas, uma vez que o tempo da noite, que durante o Inverno era reservado ao estudo, passava a ser "todo livre para recreação" (Ibidem) e que as tardes dos dias de férias eram deixadas "livres para decentes divertimentos ou exercicio de passeio" (Ibidem).

Vendo bem, os exercícios apareciam fundamentalmente associados a uma interpretação higiénica do movimento. Os momentos dispensados nestes estabelecimentos às práticas físicas, salvo os casos dos Colégios dos Nobres e de Mafra, pareciam unicamente favorecer o relaxamento, o divertimento, o movimento não sistemático e lúdico, no intuito de aliviarem as tensões de uma vida demasiado monótona e sedentária.

Nos finais do século XVIII, a generalidade das instituições de ensino portuguesas pareciam encarar o exercício como passeio ao ar livre e recreação. Mesmo a dança e a esgrima, que eram contempladas nos Colégios dos Nobres e de Mafra e constituíam uma prática sistemática, pelo menos, durante uma parte do ano, poucas vezes apareciam nomeadas nos documentos a informarem-nos sobre a organização dos estabelecimentos escolares dos dois lados do Atlântico. De facto, apesar das diferenças de pormenor, as prescrições contempladas no documento regulador do Seminário de Pará e Maranhão dizem-nos que, nesse estabelecimento, se seguiam ideias condicionadoras dos planos de estudo anteriormente mencionados. Neste caso particular, para além de dois pequenos períodos de descanso - um, entre as 11,00 e as 11,15 horas, e outro, depois do almoço, das 12,45 às 13,00 horas - só encontrámos um período de uma hora, entre as 16,00 e as 17,00 horas, ou, nos meses de Junho, Julho e Agosto, das 17,00 as 18,30 horas. Somente nos dias feriados é que esse período de 
repouso se prolongava por duas horas e meia, precisamente entre as 16 e as 18,30 horas. Todavia, estipulava-se que em cada semana existisse um dia de passeio, passando a dois nos meses de Julho, Agosto e Setembro (11, p. 227 e 229).

Por certo, reconheceremos a mesma concessão educativa no Recolhimento de N. Senhora da Glória do lugar da Boavista, de Pernambuco, que se empenhava na educação de crianças e adolescentes do sexo feminino. É claro que, direccionando-se à educação de raparigas, as normas apresentavam algumas especificidades, no entanto, mais reforçadoras do que prejudicadoras da nossa perspectiva. De facto, às educandas apenas lhes eram concedidas duas interrupções diárias de trinta minutos, uma ao jantar e outra à ceia. $\mathrm{O}$ mais curioso é que elas, durante este tempo, só tinham permissão para conversarem "umas com as outras sem estrondo de palavras, ou rizadas descompostas; mas sim com muita modestia, e civilidade, guardando-se respeito umas as outras" (13, p. 111) independentemente da idade ou das posses.

Para além destas pequenas interrupções diárias, havia um outro período a desenrolar-se entre as 17,30 e as 18,00 horas e destinado à aprendizagem da música ou de algum instrumento. As alunas que não quisessem aprender estes saberes, podiam então ir passear para a "cerca", desde que tivessem autorização da directora. De qualquer modo, os verdadeiros tempos de recreação seriam os Domingos, dias santos e outros feriados, porque nesses dias as educandas podiam ir divertir-se para junto da tal "cerca" a partir das 16,00 horas. De acordo com as disposições dos estatutos de 1798, as alunas deviam gozar o seu divertimento em plena liberdade, devendo até a mestra familiarizar-se com elas e ensinar-lhes jogos que considerasse lícitos (Ibidem, p. 107 e 112). Entrados no século XIX, e passando ao norte de Portugal, continuámos a encontrar nos horários escolares de algumas instituições educativas tempos especialmente destinados para que as crianças e os adolescentes pudessem concretizar os jogos e as brincadeiras do seu gosto.

O plano de estudos para a educação dos porcionistas do Real Colégio de Nossa Senhora da Graça e Meninos Órfãos da cidade do Porto, elaborado em 1813, estipulava "recreação honesta em certas horas, e jogos inocentes dentro do Collegio menos o de car- tas" (25, p. 6), bem como o "passeio humas vezes por outras em cada semana" (Ibidem).

O mesmo reconhecimento da utilidade dos movimentos do corpo e dos jogos infantis para a criança encontrava-se no Seminário de S. Caetano, em Braga, destinado à educação dos meninos órfãos e dos expostos. Através do plano de educação deste estabelecimento feito em 1801 pelo Arcebispo de Braga, Fr. Caetano Brandão, foi-nos possível constatar que durante o Inverno e o Verão existiam dois períodos ditos de recreio, aproveitados certamente pelas crianças para se ocuparem com jogos e exercícios variados. No Inverno e no Verão o primeiro período de recreação estendia-se entre as 12,45 e as 13,00 horas, embora nesta última estação do ano pudesse este intervalo ser mais longo. Relativamente ao segundo período, no Inverno ele desenvolvia-se entre as 16,30 e as 18,00 horas e no Verão entre as 17,30 e as 19,00 horas. Contudo, nos dias feriados os recreios podiam ser maiores, principalmente naqueles dias em que as crianças não fossem a passeio. Além disso, nos dias de "maior calor" havia o cuidado de regularem-se as horas de recreio e estudo para os meninos respirarem e terem "o desafogo preciso" (12, p. 44).

Para além destes tempos destinados às recreações, o regulamento deste seminário determinava que as crianças tivessem também passeios com o objectivo de "respirarem das suas fadigas e para se vigorarem tomando novo alento" (Ibidem, p. 46 e 47). Os domingos e as quintas-feiras eram os dias aprazados para esse efeito. Porém, se algum dia festivo não calhasse à quinta-feira, seria nesse dia que se realizaria a actividade física e caso houvesse, na mesma semana, dois dias festivos, ficaria ao arbítrio do Reitor a decisão de haver ou não, em todos eles, passeios.

Significativo é o facto do regulamento não se esquecer das crianças que estavam com alguma doença ou em convalescença, estipulando caber ao Reitor regular-lhes os dias dos passeios, desde que fossem indicados como terapêutica (Ibidem, p. 47).

Olhando para as ideias e as práticas relativas à educação física nos finais da segunda metade do séc. XVIII, vemos convergir duas tendências a propiciarem um movimento favorável ao desenvolvimento do corpo. De um lado, as actividades físicas e os jogos legados pela tradição e, do outro, concepções médicas e peda- 
gógicas mais atentas às condições higiénicas e aos factores de desenvolvimento dos indivíduos, que iriam propiciar às entidades administrativas dos estabelecimentos educativos olharem para as actividades físicas das crianças como um momento de descontracção e de formação. Todavia, as medidas contempladas nos estabelecimentos referidos indicavam que se seguia uma concepção de Educação Física fundamentalmente higiénica ou tradicional. No fundo, elas confirmavam a ideia exposta por Jorge Crespo de que, na transição do séc. XVIII para o séc. XIX, se registava a presença de duas linhas de força dominantes e com passados e futuros desiguais. De facto, constatava-se a permanência de técnicas corporais de uma minoria social privilegiada, para quem o corpo se formava conforme os "critérios de elegância, implicando gestos plenos de formalismos artificiais" (15, p. 544) e um fomento de práticas corporais fundamentadas "em pressupostos higiénicos e pedagógicos" (Ibidem) a reclamarem "a intervenção do próprio corpo na sua formação" (Ibidem), sobrevalorizando aquelas que se mostravam válidas para o desenvolvimento da população em geral.

De qualquer modo, embora fosse notória alguma dificuldade em assimilar verdadeiramente o discurso médico-pedagógico que então se ia disseminando, a generalidade das instituições educativas revelava maior predisposição para encarar os aspectos relacionados com o desenvolvimento físico, integrando-os num plano mais vasto de formação. Os rígidos horários, sobrecarregados de aulas, horas de estudo e tempos de oração, registavam também momentos de recreação ou espaços dedicados a práticas físicas. Desses planos de estudo ressaltava a referência, sobretudo, aos passeios, o que parecia traduzir uma adesão à preocupação dos médicos e pedagogos em devolverem o corpo à natureza. Em concreto, procurava-se com esta medida recuperar energias necessárias a uma maior eficácia da aprendizagem e propiciar ocasiões de desenvolvimento físico, capazes de favorecerem a robustez do corpo.

À medida que se avançava no século XIX, os estabelecimentos de ensino pareciam querer disponibilizar, no tocante à educação física, condições para a prática de actividades tradicionalmente associadas à aristocracia. A esgrima e, sobretudo, a dança apareciam agora especialmente apelativas nos planos de estudos. O Colégio de São João Baptista, instalado no desig- nado Palácio do Patriarca, situado na Junqueira, pretendia-se uma instituição educativa modelar e, por isso, incluía, no "ramo útil", a equitação e, no "ramo agradável”, a dança (5, Ms. 5250); no plano de estudos do Colégio da Santíssima Trindade, mencionava-se a dança, a esgrima e a picaria (3, Ms. 5225); no do Colégio de São Pedro de Alcântara, do bacharel Clemente José de Mendonça, indicava-se que nele se ensinava a dança e a esgrima (6, Ms. 4209); no "Novo Plano" do Colégio Nacional, só se fazia referência à dança, por isso, nele não se praticaria, pelo menos com carácter sistemático, nem a equitação nem a esgrima. Contudo, este documento dava especial importância à educação física e, sobretudo, apresentava uma muito interessante justificação para a sua prática neste estabelecimento educativo. Dizia o texto que a "dança tem a dobrada vantagem de dar vigor ao corpo, garbo, e firmeza aos movimentos; por isso, e como parte da educação phisica, e como parte de educação politica" (4, Ms. 5242) se considerava importante incluí-la no plano de estudos do referido colégio.

A inclusão destas modalidades no plano educativo de instituições escolares, nos finais do Antigo Regime, parece querer demonstrar que estas se sentiam na necessidade de estarem sensibilizadas, por um lado, para os aspectos do desenvolvimento físico e, por outro, para as exigências sociais das famílias dos potenciais alunos. Já não bastaria propiciar tempos de recreação e passeios aos que desejavam aprender, nos colégios, uma educação adequada a posições sociais prestigiadas; era, do mesmo modo, preciso garantir a capacidade de dotar o corpo de posturas condizentes às expectativas criadas. No sentido de se conformar a educação dos jovens aos ditames das conveniências da vida social das classes mais abastadas da época, os colégios, normalmente, reservavam espaços nos planos educativos para as "artes liberais". Como é natural, as artes disponibilizadas variavam de estabelecimento para estabelecimento, tanto mais que não era fácil reunir as condições necessárias para a sua prática. O plano do Colégio de São Pedro de Alcântara, bastante ambiciosamente, declarava o seguinte: "As artes liberais, que no Collegio se ensinão, são a dansa, a musica tanto vocal, como instrumental; o jogo d'arma a ser espada, florête, e sabre; a miniatura, e mesmo a pintura; cada qual se applicará áquella, que 
quizer; ou mesmo a todas: con tanto que as dispezas serão por sua conta. Será indifferente o aprender cada qual a arte, que quizer; mas a dança, e a música, serão indispensáveis, e especialmente aos pensionistas estáveis; porque a primeira ensina o garbo, e maneio do corpo; e a segunda adóça os movimentos do coração, e da alma; e torna o homem mais meigo, e sensível (6, Ms. 4209). Ou seja, a dança e a música revelavam-se como aspectos fundamentais numa boa formação e, especialmente, apreciadas na vida social. Perspectivada a partir da concepção de Educação Física da época, a dança, ao ser considerada como actividade primordial, ajudava a definir um ideal estético do corpo e dos seus desempenhos para a generalidade das pessoas de prestígio. Por outro lado, como se pode verificar através dos já citados planos de estudo, inclusivamente o do Colégio de São Pedro de Alcântara, existiam outras medidas devidamente valorizadas e a apontarem, igualmente, para a permanência de uma compreensão aristocratizante da Educação Física. Assim, continuavam a verificar-se as mesmas tendências já apontadas para as últimas décadas do século XVIII, ou seja, técnicas corporais valorizadas para uma minoria social privilegiada, assentes em critérios de elegância barroca e práticas corporais fundamentadas "em pressupostos higiénicos e pedagógicos" (15, p. 544), desejosas da "intervenção do próprio corpo na sua formação (Ibidem). Aliás, a vigência destas duas tendências era bem clara nos documentos do referido Colégio de São Pedro de Alcântara, porque neles, para além das práticas já mencionadas, se advogava que com "exercícios fortes, applicados con prudência, se tornão os rapazes ágeis, robustos, e membrudos" (6, Ms. 4209). Mais, o seu autor afirmava peremptoriamente: "Eu pois adôtarei estes exercícios: jogos balísticos, a esgrima, a carreira, a luta, tudo porei em uso, applicando-os a cada um segundo a sua idade, e constituição, intimamente persuadido, de que com elles, e com a simplicidade da meza banirei do meu Collêgio, senão em tudo, ao menos em parte, esse vício cruél estragador da juventude, e que tem seu assento commum entre a mocidade clausurada" (Ibidem).

O mínimo que se pode dizer de tão ilustrativa declaração é que se tratava de uma verdadeira profissão de fé, nas capacidades da Educação Física, nos alvores da contemporaneidade.

\section{CONCLUSÃO}

Na sequência das indicações de vários autores sobre a educação física, as quais, à medida que se caminhava para o final do Antigo Regime, mais se iam acentuando, os colégios sentiram a necessidade de incorporarem nos seus planos de estudos disposições favoráveis à recreação e à manutenção da saúde. Ora, da análise sobre as ideias e as práticas relativas à educação física nos finais da segunda metade do séc. XVIII, vimos que elas se desenvolviam de acordo com duas tendências: de um lado, as práticas físicas e os jogos legados pela tradição e, do outro, concepções médicas e pedagógicas mais atentas às condições de desenvolvimento dos indivíduos, que se concretizavam em actividades de descontracção e de formação do corpo pensadas para se articularem com as de natureza intelectual. No entanto, as disposições contempladas nos planos de estudo dos colégios indicavam que se privilegiava uma concepção de educação física fundamentalmente higiénica ou tradicional. Aí se destacava, sobretudo, a permanência de técnicas corporais de uma minoria social privilegiada, para quem o corpo se devia conformar a critérios de elegância, definidos por gestos plenos de formalismos, e também práticas corporais fundamentadas em preocupações higiénicas e pedagógicas, válidas para o desenvolvimento da população em geral. De qualquer modo, embora fosse notória alguma dificuldade em assimilar, verdadeiramente, o discurso médico-pedagógico que então se ia disseminando, a generalidade dos estabelecimentos educativos revelava maior predisposição para encarar os aspectos relacionados com o desenvolvimento físico, integrando-os num plano mais vasto de formação, onde a sucessão de horas dedicadas às aulas, ao estudo e à oração, eram, de algum modo, amenizadas com momentos de recreação ou com espaços dedicados a práticas físicas. Nesses planos de estudos sobressaía sobretudo a insistência nos passeios, normalmente justificados como adequados à recuperação de energias necessárias a uma maior eficácia da aprendizagem, bem como propiciadores de ocasiões de desenvolvimento físico.

À medida que se avançava nas primeiras décadas do século XIX, os colégios, no tocante à educação física, pareciam querer oferecer condições para a prática de actividades tradicionalmente associadas à aristocra- 
cia. A esgrima e, mormente, a dança apareciam então particularmente atractivas nos planos de estudos.

Ora, a inclusão destas modalidades nos planos educativos destes estabelecimentos de ensino nos finais do Antigo Regime parecia traduzir, por um lado, as preocupações com o desenvolvimento físico e, por outro, as exigências sociais das famílias dos potenciais alunos. Por certo, os pais queriam filhos saudáveis e, para isso, eram necessários os tempos de recreação e passeios; mas a prática da esgrima e da dança, além de servir a condição física dos jovens, assegurava posturas do corpo adequadas a posições sociais prestigiadas. Um corpo saudável só atingia a sua plenitude se fosse capaz da elegância do gesto delicado no momento adequado.

\section{CORRESPONDÊNCIA}

José Vítor Ferreira

Faculdade de Ciências do Desporto

e de Educação Física

Universidade do Porto

Rua Plácido Costa, 91

4200-450 Porto

Portugal

jferreira@fdcef.up.pt 


\section{FONTES E BIBLIOGRAFIA}

\section{FONTES MANUSCRITAS}

1 ANTT [1778-1788]. Real Mesa Censória: Plano do Collegio de S. Patricio sito na Costa do Castello, Cx. $n^{\circ} 362$, Doc. $\mathrm{n}^{\circ} 4202$.

2 ANTT (1791). Real Mesa Censória: Noticia. Casa de Educação, e Collegio de ...Silverio .... em Lisboa, Cx. $\mathrm{n}^{\circ}$ 512, Doc. $n^{\circ} 5193$.

3 ANTT (1815). Real Mesa Censória: Plano do Collegio da Santissima Trindade estabelecido na Rua da Procissão no Palacete $n^{\circ} 50$ e 51, Cx. $\mathrm{n}^{\circ}$ 512, Doc. 5225

4 ANTT (1817). Real Mesa Censória: Novo Plano de uma casa de educação intitulada Collegio Nacional, Cx. n 512, Doc. 5242.

5 ANTT (1818). Real Mesa Censória: Publicação do Collegio de S. João Baptista, Cx. n 512 , Doc. 5250.

6 ANTT (1819). Real Mesa Censória: Plano de um novo Collêgio de educação, e instrução da Juventude portugueza dedicado a seus compatriotas os Chefes, e Pais de familias, amantes de seus filhos por Clemente Joze de Mendonça B.el Formado, Cx.n ${ }^{\circ}$ 362, Doc. 4209.

\section{FONTES IMPRESSAS E BIBLIOGRAFIA}

7 Aguilar, M. B. d. (1935). O Real Colégio dos Nobres (17611837). Lisboa.

8 Almeida, F. J. d. (1791). Tratado da educaçaõ physica dos meninos, para uso da naçaõ portugueza. Lisboa: Na Officina da Academia Real das Sciencias.

9 Andrade, A. A. B. d. (1981). A reforma pombalina dos estudos secundários (1759-1771): Contribuição para a história da pedagogia em Portugal. Coimbra: Coimbra Editora.

10 Arnaud, P. (dir.) (1981). Le corps en mouvement: Precurseurs et pionniers de l'éducation physique. Toulouse: Éditions Privat.

11 Brandão, D. Fr. C. (1783). Pastoral porque Sua Excellencia estabelece a regra pela qual se deve governar o seminario desta cidade interinamente. Pará. J. de Coimbra (1814). XXVIII: 224-230.

12 Brandão, D. Fr. C. (1861). Plano de educação dos meninos orfãos e expostos do Seminario de S. Caetano feito no anno de 1801. Braga: Typ. Dos Orfãos.

13 Coutinho, D. Jozé Joaquim da Cunha de Azeredo (1789) Estatutos do Recolhimento de N. Senhora da Gloria do lugar da Boavista de Parnambuco. Lisboa: Na Tipografia da Acad. R. das Sciencias.

14 Carvalho, R. d. (1959). História da fundação do Colégio Real dos Nobres de Lisboa (1761-1772). Coimbra: AtlântidaLivraria Editora.

15 Crespo, J. (1990). A história do corpo. Lisboa: Ed. Difel.

16 Dainville, F. d. (1978). L'éducation des jésuites (XVI-XVIII siècles). Paris: Éditions de Minuit.

17 Estatutos do Real Collegio de Mafra (1772). Lisboa: Na Regia Officina Typographica.

18 Ferreira, A. G. (1989). A criança no conhecimento médico de Setecentos. Separata da R. P. Pedagogia. Coimbra.

19 Ferreira, A. G. (2000). Gerar criar educar: a criança no Portugal do Antigo Regime. Coimbra: Quarteto Editora.

20 Ferreira, J. V., Ferreira, A. G. (1991). Saúde e bem-estar: uma breve análise sobre o regime de vida no barroco. Separata das Actas do I Congresso Internacional do Barroco. Porto: Faculdade de Letras.
21 Ferreira, J. V. (1999). Olhares sobre o Corpo no séc. XVIII: saúde, práticas físicas e bem-estar. Dissertação de Doutoramento. Porto: Faculdade de Ciências do Desporto e de Educação Física. Texto policopiado.

22 Franco, F. d. M. (1790). Tratado de educaçaó fysica dos meninos para uso da naçaó portugueza. Lisboa: Na Officina da Academia Real das Sciencias.

23 Laty, D. (1996). Histoire de la gymnastique en Europe. De l'antiquité a nous jours. Paris: Presses Universitaires de France.

24 Mendonça, Fr. M. d. (1776). Regulamento das escolas do Collegio de Alcobaça ordenado conforme o que determinam os Estatutos da Universidade de Coimbra, e dispõem as instruções regias, o qual por ordem do illustrissimo, e reverendissimo $D$. Abade Geral, Visitador, e reformador da Real Congregação de Santa Maria de Alcobaça da Ordem de S. Bernardo, Fr. Manoel de Mendonça do Conselho de Sua Magestade fidellissima, seu esmoler mór e donatario da comarca de Alcobaça, se formou para uso do mesmo collegio. Lisboa: Na Regia Officina Typografica.

25 Plano que deve observar-se ácerca da educaçaõ e ensino dos porcionistas, que houverem de ser admittidos, para este fim, no Real Collegio de N. Senhora da Graça, e Meninos Orfãos desta cidade do Porto (1813).

26 Proença, M. d. M. de P. e d. (1734). Apontamentos para a educaçaõ de hum menino nobre para o seu uso particular fazia. Lisboa Occidental: Na Officina de Joseph Antonio Sylva. In J. F. Gomes (1964). Martinho de Mendonça e a sua obra pedagógica. Coimbra: Universidade de Coimbra. Instituto de Estudos Filosóficos.

27 Rauch, A. (1983). Le souci du corps: histoire de l'higiéne en éducation physique. Paris: Presses Universitaires de France.

28 Ulmann, J. (1977). De la gymnastique aux sports modernes: histoire des doctrines de l'éducation physique. Paris: Librairie Philosophique J. Vrin. 